two magnets many miles apart. The action of the force appears to have been somewhat more vigorous at Stonyhurst than at Vienna, yet not only the great inflections, but even the slight irregularities of the curves were synchronous.

The trace of the Viemna magnetograph is taken from the May number of the Zeilschift dir östcrreichischen Gesellschaft fiur Meteorologie, kindly forwarded by Ur. Hann.

The range between the maximum and primary minimum at 5h. $45 \mathrm{~m}$. p.m. G.M.T. was $33^{\prime} \cdot 7$ at Vienna, and $42^{\prime \prime} \cdot \mathrm{r}$ at Stonyhurst; and between the same maximum and the secondary minimum at $10 \mathrm{~h} .45 \mathrm{~m}$. p.m. was $24^{\prime} \cdot \mathrm{I}$ at Vienna, and $34^{\prime \circ} \mathrm{o}$ at Stonyhurst.

Both the self-recording magnetographs were made by Adie, and the time scale is the same for both curves; it is therefore very easy to identify the synchronous movements.

At Stonyhurst G.M.T. is adopted, and the longitude of Vienna is $\mathrm{Ib} .5 \mathrm{~m} .3 \mathrm{r} \cdot 3 \mathrm{~s}$. E. of Greenwich,

Stonyhurst Observatory, May 27

\section{Luminous Painting}

Nil novi sub sole.-The Japanese, nine hundred years ago, seem to have been practically acquainted with the art of luminous painting, and thus to have anticipated Mr. Balmain. In looking through the article "ye" (pictures) in the SinicoJapanese Fncyclopædia, "Wakan san sai dzu-ye" (illustrated De.scription of the Three Powers, i.e., Heaven, Earth, and Man), I recently came upon a passage, of which the following slightly condensed rendering may perhaps be of some interest to your readers :-

"In the Rui-yen (Lei-yuen, Garden of Sundries-a sort of Chinese Collectanea) we read of one Siu Ngoh, who had a picturc of an ox. Fivery day the ox left the picture-frame to graze, and returned to sleep within it at night. This picture came into the possession of the Emperor T'ai Tsung, of the Sung dynasty (A.D. 976-998), who showed it to his courtiers, and asked them for an explanation, which none of them, however, could give. At last a certain Buddhist priest said that the Japanese fornd some nacreotis substance within the flesh of a kind of oyster they picked up when the rocks were bared at low tide, and that they ground this into colour-material, and then painted pictures with it which were invisible by day and luminous by night."

"No doubt," adds the author of the Encyclopxdia, "when it is said that the ox left the picture-frame during the day to go a-grazing, it is meant simply that during the day the figure of the ox was not visible."

Arts Club, June I

\section{Brain Dynamics}

There are probably aung the readers of NATURE some helievers in the Freedom of Volition, to whom the discussion on thie above subject has not hitherto appeared to reach the knottiest point of the controversy.

The more old.fashioned supporters of the doctrine of Frec Will frequently insisted on the sense of Responsibility as the crucial proof that the will is free, probably because few of their opponents were ready to face the possible, or supposed, moral consequences of the denial of responsibility. The proof is essentially weak, and $\mathrm{Mr}$. Romanes has well exhibited its weak ness in NATURE, vol. xxii. p. 76. IIis "Prince of Denmark" has incleed so little of method in his madness that $I$ am nat disposed to think it curious that both Prof. Clifford and Mr. Tolver Preston should have left him out of their play. Hc may well exclaim "What should such fellows as I do, crawling between earth and heaven? We are arrant knaves all ; believe none of us." Surely the sense of Responsibility is not the origin, but is one of the results of the Scnsc of Freedom. I.ogically the Sense of Freedom is the justification of the sense of responsibility. Lis torically it is, no doubt, its antecedent; for while both are, as much as any other faculties of brute and man, results of evolution, the refincment of the conception of morality, and therefore probably the conception itself, has evidently originated long after the consciousness of volition. Experimentally the sense of responsibility is weakened or destroyed, either psychol gically, as where the freedom of the actor is controlled, or physiologically, as where volition is suspended in sleep, or is impaired by lesion of the anterior lobes of the brain, in all which cases the sense of responsibility suffers corresponding loss. It seems to me strange that Mr. Romanes should suppose the doctrine of Free Will to bave been conceived and continued in order to justify that Moral Sense which is esentially a consequence of it (though capable finally of being presented as onc among other motives in certain acts of volition). It lies with those who think with Mr. Romanes to account, on their own hypothesis, for the development of so universal, obtrusive, irrational, and indeed "nonsensical" an instinct as, according to that bypothesis, the sense of responsibility is. Others will see in it a rcsult of the Sense of Freedom of Volition, when combined with the intellectual perception of the consequences, to the individual or to the race, of human acts (the latter perception being the cumulative result of inherited experiences). This Sense of Frcedom of Volition is the real II amlet.

We possess, or appear to ourselves to possess, the conscious ness of the power of choosing between alternative motives. It is unsafe merely to give the lie direct to this consciousness, lest we thereby destroy the validity of the cvidence, also derived through consciousness, of all those facts on which any law of nature, and Causal Sequence itself, is based. The consciousness of power is derived from the sense of work done, as against resistance, e.g., the consciousness of muscular power is derived from a class of sensations produced on the organism by resistance, these sensations being created by, and consequently associated with, the conversion of potential energy stored up in the brain into kinetic energy transmitted through the nerves and muscles, an:t it bears no psychological resemblance to the consciousness of sensations of which the brain is the passive recipient. Similarly, the consciousness of the power of volition is derived from the sense of work done, in this case wholly within the brain, in the selection between alternative motives, and it bears no psychological resemblance to the consciousness of the motives themselves. And $\mathrm{so}$, too, just as the sense of lassitude is produced by excess of work donc as against physical resistance, so is a sense of discomfort produced by expenditure of potential energy, when acts of volition are performed against powerful emotion:.

It appears to me that the Necessitarian should be able on his part to show that this sense of work performed in choosing betwecn motives is fictitious, or that the energy above mentioned has no existence. This will not be done solely by holding even the terrors of omnipotent Causal Sequence over the head of the advocate of Free Will. The latter considers volitions to be, not indeed "uncaused" in the sense of occurring without antecedent cmotions, or without expenditure of energy in choosing between the emotions, yet not to be rigidly determined by those emotions. Ife need not inquire whether a man be "unfortunate" in the capricious character of human acts as compared with other phenomena. But he on his part has to show (and certainly no scientific mind will underrate the magnitude of the task) that phenomena of volition do, paradoxical as it may scem, constitute a class by themselves, their relation to pluysical causation bein perhaps comparable to that in which the phenomena of life stand to the laws of inorganic chemistry, a relation of addition, not of contradiction.

W. Cr.eMENT LEY

I shotind like to state, in 'reply to Mr. Ceorge Romanes' letter (NATURF, vol. xxii. p). 75), that the question of "Responsibility" was left out of my letter (NATURE, vol. xxii. p. 29) partly because it seemed to me a separate or somewhat distinct subject, and partly from the fact that this matter had been already considered by me in connection with a paper on "Nata. ral Science and Morality," to he published in the Fournal of Sicnce for July next; and to this, therefore, I would venture to refer those who may be interested in this question.

I may mercly conclude by saying that, while otherwise fully endorsing Mr. Romanes' letter, there is only one point on which I should be disposed to disagree with him, viz., in regard to his suggested view that the doctrine of strict causal scquence in nature would tend to show the feelings of Responvibility, Praise, and Blame to be "de titute of any rational justification." For there appear to me to be grounds for believing that a scientific and rational explanation of these feelings exists.
London, June
S. 'Tolver Presto:

\section{Vortex Atoms}

WhILE thanking Mr. G. II. Darwin for his ofservations on one or two passages in my paper "On the Ihysical Aspects of the Vortex-Atom Theory," which, as they stand, may no doubt tend to convey an incxect impression, I may state that the illus- 